\title{
Epoxylite Influence on Field Electron Emission Properties of Tungsten and Carbon Fiber Tips
}

\author{
Shady S Alnawasreh, Ala'a M Al-Qudah, Mazen A Madanat, \\ Emad S Bani Ali, Ayman M Almasri, Marwan S Mousa*
}

Department of Physics, Mu'tah University, Al-Karak 61710, Jordan

*Correspondence to:
Mousa MS,
Tel: +962-79-565-9761
Fax: +962-3-2375540
E-mail: marwansmousa@yahoo.com

Received July 20, 2016

Revised October 5, 2016

Accepted November 18, 2016
This investigation deals with the process of field electron emission from composite microemitters. Tested emitters consisted of a tungsten or carbon-fiber core, coated with a dielectric material. Two coating materials were used: (1) Clark Electromedical Instruments Epoxylite resin and (2) Epidian 6 Epoxy resin (based on bisphenol A). Various properties of these emitters were measured, including the current-voltage characteristics, which are presented as Fowler-Nordheim plots, and the corresponding electron emission images. A field electron microscope with a tip (cathode) to screen (anode) distance of $10 \mathrm{~mm}$ was used to electrically characterize the emitters. Measurements were carried out under ultrahigh vacuum conditions with a base pressure of $10^{-6}$ Pascal $\left(10^{-8} \mathrm{mbar}\right)$.

Key Words: Field electron emission, Composite micro-emitters, Dielectric materials, Fowler-Nordheim plots, Field electron microscope

\section{INTRODUCTION}

Developing electron sources with better characteristics and lifetimes is a very important task for applied electronics. This paper is about novel forms of field electron emission (FE) source, and continues work previously reported by the Mutah University field emission group (Alnawasreh et al., 2015; Mousa et al., 2012).

The first observation of what appears to be an FE-initiated electric discharge was made by Winkler (1744). The first clear review of experimental FE phenomena (then called "autoelectronic emission") was given by Lilienfeld (1922). Many modern emitters operate in the so-called "cold field electron emission (CFE)" regime, which is a regime where (i) the electrons in the emitting region are effectively in local thermodynamic equilibrium and (ii) most electrons escape by deep tunneling from states close to the emitter's Fermi level (Forbes, 2012; Forbes et al., 2015). The first scientist to attempt a presumptive theory for the CFE regime was Schottky (in 1923). Fowler and Nordheim (in 1928) developed the first appropriate theory for explaining field emission related phenomena. This theory was later improved by Murphy and Good (1956) and many others.

CFE from a bulk emitter is described by approximate equations known as Fowler-Nordheim-type (FN-type) equations (Forbes, 2012; Forbes et al., 2015). The technically complete (generalized) FN-type equation for the local emission current density $J_{\mathrm{L}}$ can be written in the form (Forbes, 2012; Lilienfeld, 1922).

$$
J_{\mathrm{L}}=\lambda_{\mathrm{L}} a \phi^{-1} F^{2} \exp \left[-v_{\mathrm{F}} b \phi^{3 / 2} / F\right]
$$

Where, $a$ and $b$ are the first and second Fowler-Nordheim constants, respectively. The barrier form correction factor $v_{\mathrm{F}}$ accounts for the particular shape of the potential barrier model to be used, and the local pre-exponential correction factor $\lambda_{\mathrm{L}}$ formally takes into account all other factors that influence the emission. Of course, these two correction factors also depend on the applied field $F$, as well as material parameters. This equation has been called the "technically complete FN-type equation for $J_{\mathrm{L}}$ in terms of $\phi$ and $F$ " (Forbes, 2012). For the Schottky-Nordheim (SN) barrier (Forbes,

(a) This is an open-access article distributed under the terms of the Creative Commons Attribution Non-Commercial License (http://creativecommons.org/licenses/by-nc/4.0) which permits unrestricted noncommercial use, distribution, and reproduction in any medium, provided the original work is properly cited.

Copyrights @ 2016 by Korean Society of Microscopy 
2012), the barrier form correction factor is given by a welldefined special mathematical function $\mathrm{v}_{\mathrm{F}}$, sometimes called the "principal SN-barrier function".

General aims when manufacturing composite micropoint cathodes have been to avoid degradation of the electron emitter tip due to ion sputtering processes during emission, to obtain an electron emitter with long lifetime, and improve the emission characteristics (Mousa, 1990; Mousa \& Al Share, 1999; Mousa et al., 2001).

The objective of the present investigation is to study the impact of dielectric coatings, using two different forms of resin: (1) Clark Electromedical Instruments Epoxylite resin ("CEI resin") and (2) Epidian 6 epoxy resin (based on bisphenol A) ("E6 resin"). We examine the effects on the characteristics and emission stability of tungsten and carbonfiber micro-emitters coated with these resins. Observations made include current-voltage $(I-V)$ characteristics, plotted using FN plots, and electron emission images, observed in a field electron microscope (FEM).

A

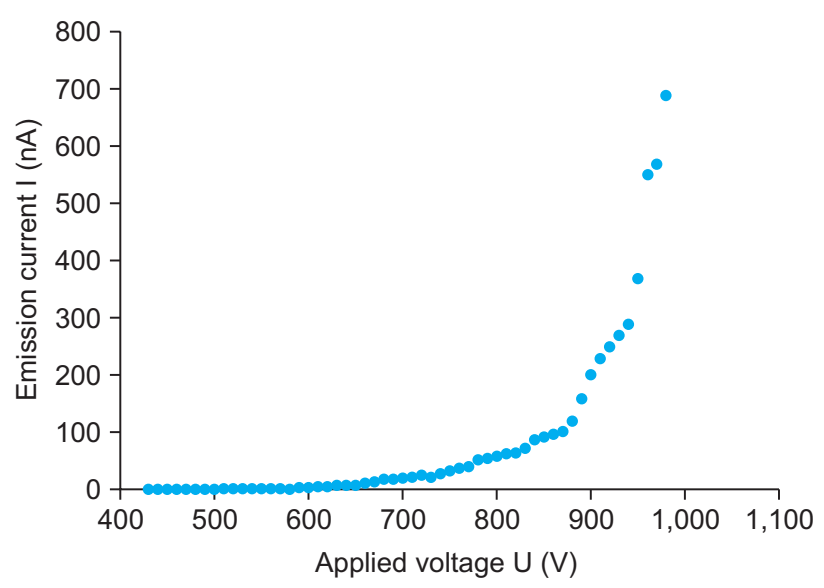

\section{MATERIALS AND METHODS}

Procedures for coating a tungsten (W) tip have been described elsewhere (Al-Qudah et al., 2015; Latham \& Mousa, 1986; Madanat et al., 2015; Mousa et al., 2015). The micropoint emitters used were electrolytically etched from $0.1 \mathrm{~mm}$ diameter tungsten wires (99.95\% purity), using a 2 $\mathrm{M}$ solution of $\mathrm{NaOH}$ and for carbon fiber tip were using a $0.1 \mathrm{M}$ solution of sodium hydroxide solution (Mousa et al., 2015). Then the tips were ultrasonically cleaned. The coating procedure involves slowly dipping the tip into the dielectric, and then carefully removing it to ensure that only a thin film remains on the tip surface. The tip is then carefully transferred to an oven and subjected to a curing cycle of thirty minutes at $100^{\circ} \mathrm{C}$ to drive off the solvents, followed by another thirty minutes at $185^{\circ} \mathrm{C}$ to complete curing of the resin.

The coated tips were studied in evacuated FEMs with a diffusion pump system having an additional liquid nitrogen trap. Base pressures of $10^{-6}$ Pascal $\left(10^{-8} \mathrm{mbar}\right)$ have been

\section{B}

$1,000 / \mathrm{U}(1 / \mathrm{V})$

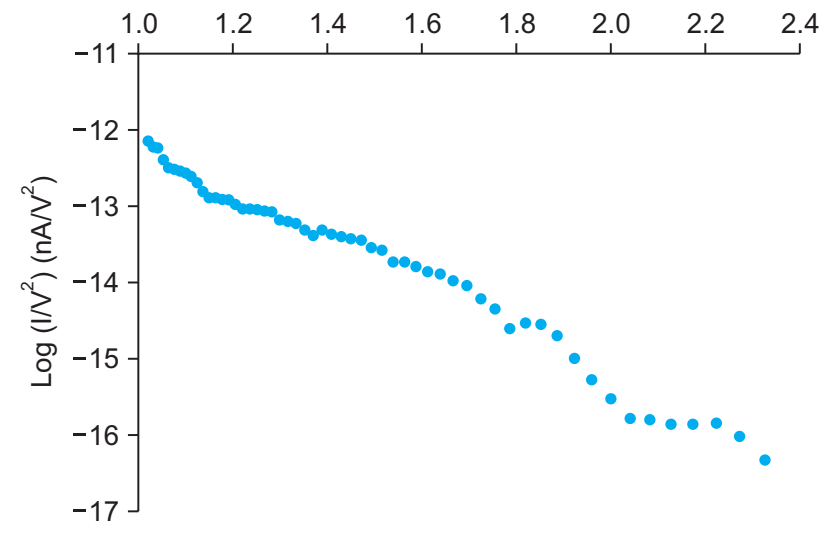

Fig. 1.1. (A) The current-voltage $(I-V)$ characteristics of a clean tungsten tip, taken as voltage increases; (B) related Fowler-Nordheim (FN) plot. The applied voltage is in the range of 430 to $980 \mathrm{~V}$. The FN-plot slope is $-3,009$ decade $\mathrm{V}$.
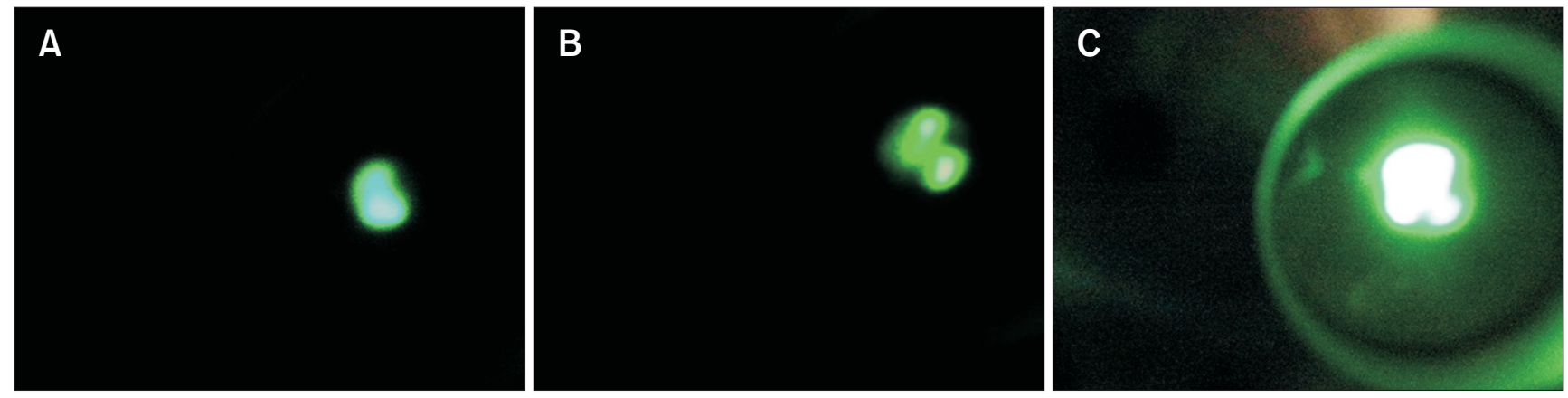

Fig. 1.2. Images of field emission from clean tungsten tip are distributed in several spots, when increasing the voltage. The emission current was getting brighter. As can be seen from the emission images, emission spots start to become brighter or bigger as the voltage was increased. Image details are: (A) $780 \mathrm{~V}$, $51 \mathrm{nA}$; (B) $870 \mathrm{~V}, 100 \mathrm{nA}$; (C) $960 \mathrm{~V}, 5.50 \mathrm{nA}$. 
reached after baking the system at a temperature of $200^{\circ} \mathrm{C}$ for 12 hours with liquid nitrogen added to the trap. The separation between the tip apex (cathode) and the screen (anode) was standardized at $\sim 10 \mathrm{~mm}$ using a current limiting resistor of $20 \mathrm{M} \Omega$. The images presented were taken by a digital camera through the window of the vacuum system. An electric high tension power supply is used to apply a negative voltage to the cathode. The emission current is measured with a Kiethley 485 auto-ranging pico-ammeter (Madanat et al., 2015; Moran Meza et al., 2015).

\section{RESULTS AND DISCUSSION}

As indicated above, tungsten and carbon-fiber microemitters

A

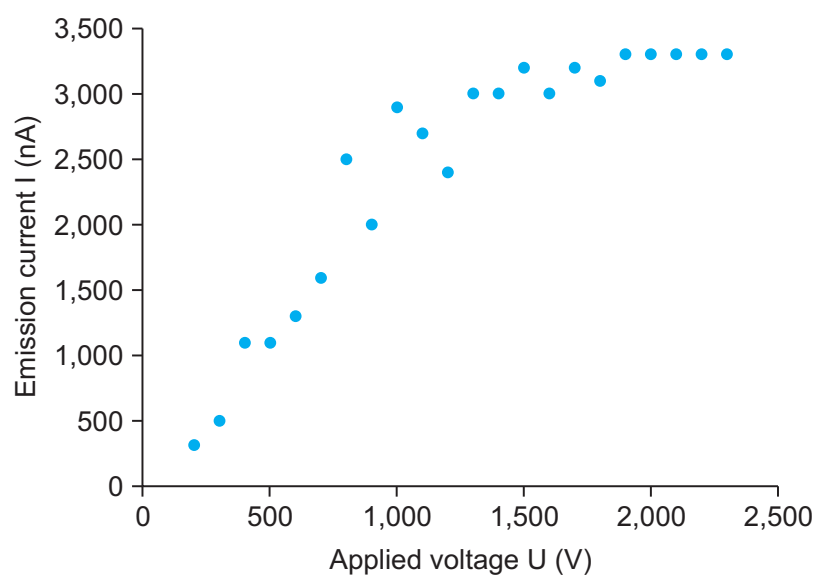

with two types of dielectric coating, namely "CEI resin" and "E6 resin", have been analyzed. Results are compared below with those obtained with clean uncoated tungsten and carbon-fiber microemitters.

\section{Composite Tungsten/CEI-Resin Emitter}

Voltage was applied to the clean tungsten tip and the $I-V$ characteristics were recorded. The emission started at $430 \mathrm{~V}$ with current $8.8 \mathrm{pA}$. Increasing the applied voltage very slowly caused an increase in the emission current; voltages applied in the range 430 to $980 \mathrm{~V}$ gave currents in the range $8.8 \mathrm{pA}$ to 690 nA, as shown in Fig. 1.1A; Fig. 1.1B shows the related FN plots. Fig. 1.2 shows how the emission image depends on the emission current.

Fig. 1.3. (A) The current-voltage (I-V) characteristics for a composite tungsten/CEI-resin tip, recorded during the first decreasing-voltage scan; (B) related Fowler-Nordheim (FN) plot for the low-field region where the $I-V$ data gives a linear FN-plot. The applied voltage is in the range $2,300 \mathrm{~V}$ down to $200 \mathrm{~V}$. The FN-plot slope is about-158 decade V.

A

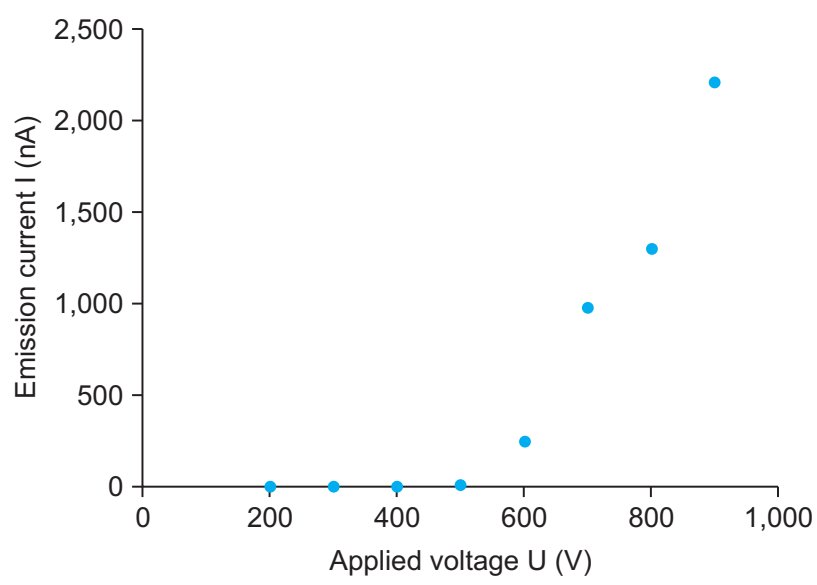

B

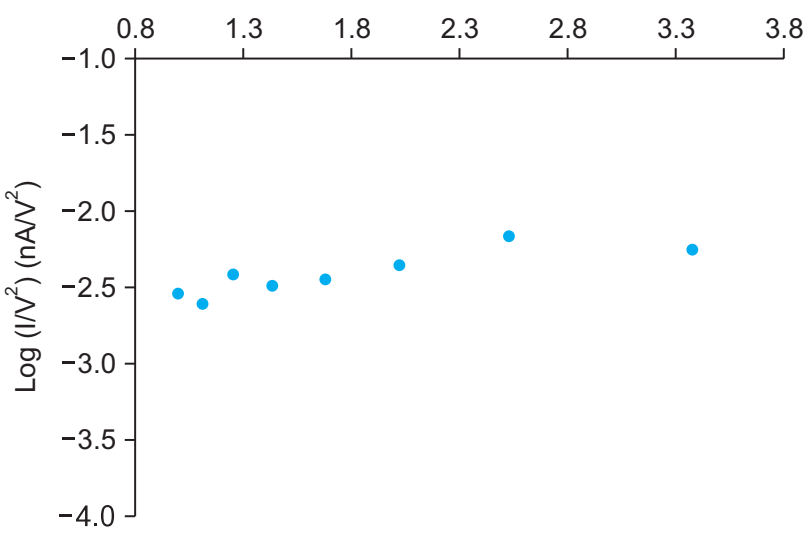

Fig. 1.4. (A) The current-voltage ( $I-V)$ characteristics for composite tungsten/CEI-resin emitter during the second increasing-voltage scan; (B) related Fowler-Nordheim (FN) plot. The applied voltage in the range of 200 to $900 \mathrm{~V}$. The FN-plot slope is $-1,148 \mathrm{decade} \mathrm{V}$. 
For the composite tungsten/CEI-resin tip, the voltage across a new (untested) emitter is slowly increased until a "switchon voltage" $V_{\mathrm{sw}}$ is reached. At this point the emission current switches on abruptly from an effectively zero value to a stable apparently saturated value, namely the "switch-on current" $I_{\text {sat }}$. At this point, $V_{\text {sw }}$ is $2,300 \mathrm{~V}$ and $I_{\text {sat }}$ is $3.3 \mu \mathrm{A}$. If the voltage is then reduced, the emission current reduces gradually. Fig. $1.3 \mathrm{~A}$ shows the $I-V$ characteristics for the first such decreasing scan, which takes place over the voltage range 2,300 $\mathrm{V}$ down to $200 \mathrm{~V}$ and the corresponding current range $3.3 \mu \mathrm{A}$ to 32 $\mathrm{pA}$. When the voltage is increased again, there is no abrupt "switch-on phenomenon", but the current increases steadily,
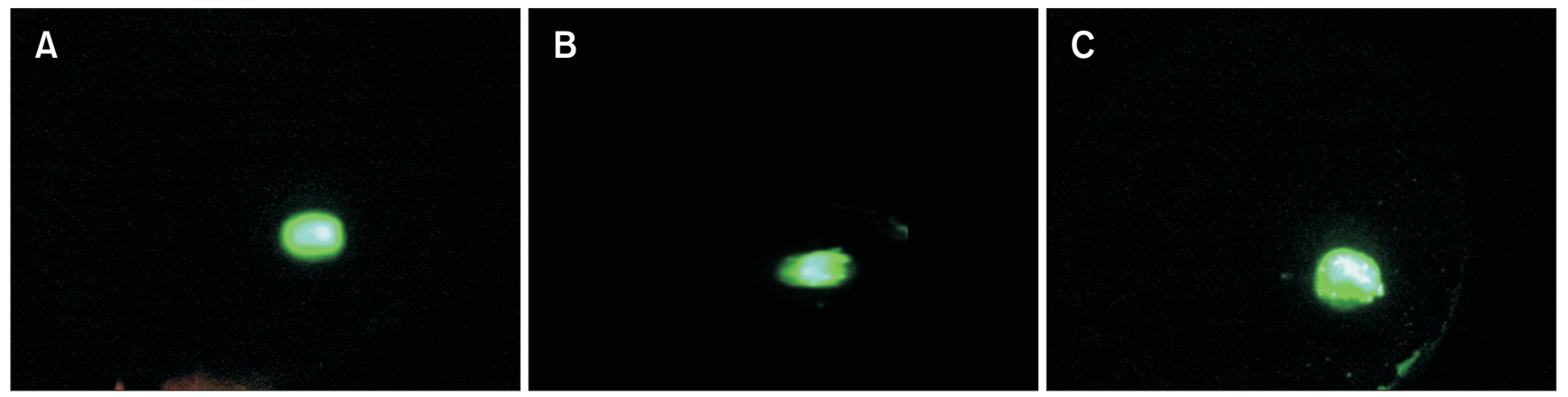

Fig. 1.5. For the composite tungsten/CEI-resin emitter, these images show that emission is relatively stable in one high brightness spot. Measurement details were: (A) 2,300 V, $3.3 \mu \mathrm{A}$; (B) 2,100 V, $3.3 \mu \mathrm{A}$; (C) 1,700 V, $3.2 \mu \mathrm{A}$; the time separation between adjacent images is 15 minutes.

A

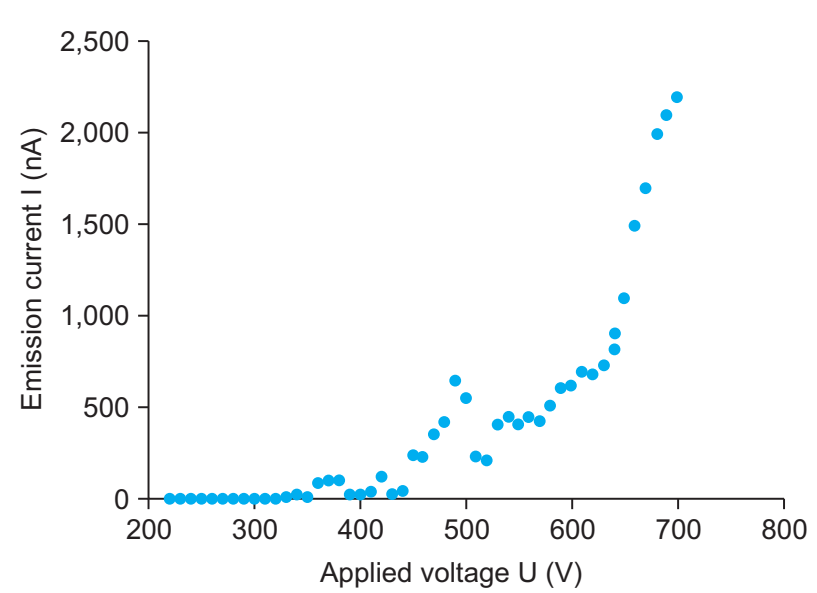

B

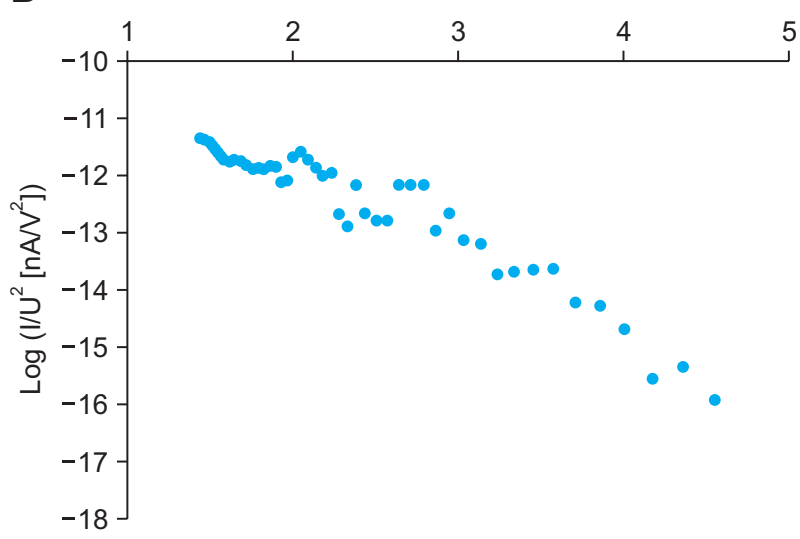

Fig. 2.1. (A) The current-voltage ( $I-V)$ characteristics for a clean carbon-fiber tip, taken as voltage increases; (B) related Fowler-Nordheim (FN) plot. The applied voltage is in the range of 200 to $700 \mathrm{~V}$. The FN-plot slope is $-1,313$ decade $\mathrm{V}$.
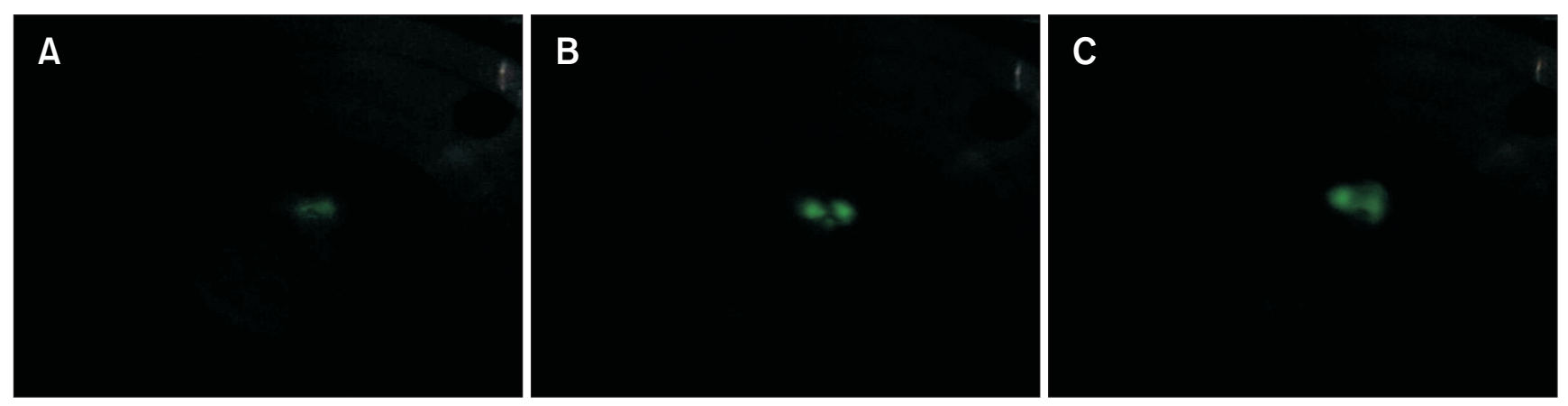

Fig. 2.2. Images of field emission of carbon-fiber tip, when increasing the voltage. The emission current was increasing. As can be seen from the emission images, emission spots start to become brighter or bigger as the voltage was increased. Image details are: (A) $660 \mathrm{~V}, 1.0 \mu \mathrm{A}$; (B) $680 \mathrm{~V}, 1.5 \mu \mathrm{A}$; (C) $700 \mathrm{~V}, 2.2 \mu \mathrm{A}$. 
as shown in Fig. 1.4A. As the voltage increases from $200 \mathrm{~V}$ to $900 \mathrm{~V}$, the current increases from $10 \mathrm{pA}$ to $2.2 \mu \mathrm{A}$. The right parts of Fig. 1.3 and Fig. 1.4 show the related FN plots. The emission images, Fig. 1.5, which are taken at 15-minute intervals, show that the emission current distribution is relatively stable.

\section{Composite Carbon-Fiber/CEl-Resin Emitter}

Voltage was applied to the clean carbon-fiber tip and the $I-V$ characteristics were recorded. Emission started at $220 \mathrm{~V}$ with current $5.5 \mathrm{pA}$. Increasing the applied voltage very slowly caused an increase in the emission current; voltages applied in range 220 to $700 \mathrm{~V}$ gave currents in the range $2.2 \mathrm{pA}$ to $2.2 \mu \mathrm{A}$, as shown in Fig. 2.1A; Fig. 2.1B shows the related FN plots.

A

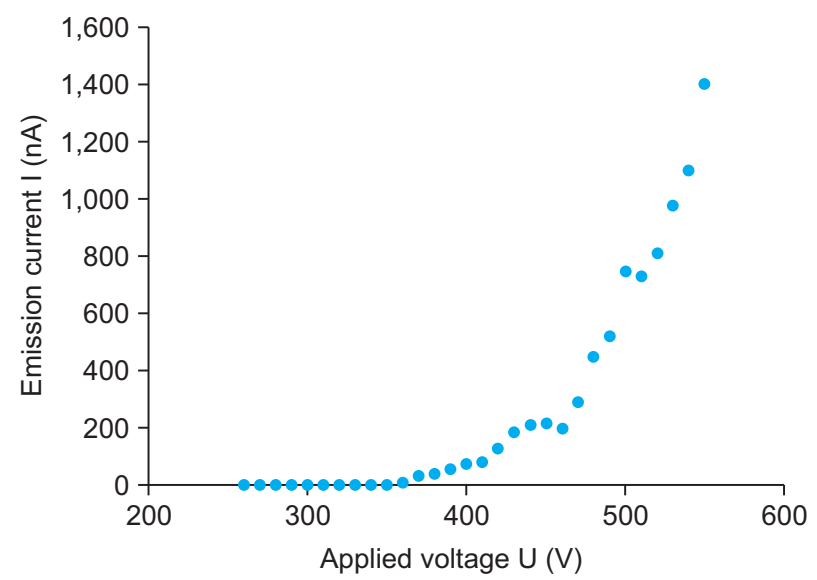

Fig. 2.2 shows the relationship between emission current and the emission images for the clean carbon-fiber tip.

With the composite carbon-fiber/CEI-resin tip, there was no "switch-on" phenomenon. Fig. 2.3A shows the $I-V$ characteristics for the first increasing voltage scan, for the voltage range 260 to $550 \mathrm{~V}$ and current range $4.5 \mathrm{pA}$ to $1.4 \mu \mathrm{A}$; Fig. 2.4A shows the immediately following voltage scan, with voltage decreasing from $550 \mathrm{~V}$ down to $150 \mathrm{~V}$ and current from $1.6 \mu \mathrm{A}$ to $1.2 \mathrm{pA}$. The right parts of Fig. 2.3 and Fig. 2.4 show the related FN plots.

Fig. 2.2 shows the relationship between the emission image and emission current for the clean carbon-fiber tip; Fig. 2.5 shows similar information for the composite carbon-fiber/ CEI-resin tip.

Fig. 2.3. (A) The current-voltage $(I-V)$ characteristics of composite carbon-fiber/CEI-resin, during the first increasing-voltage scan; (B) related FowlerNordheim (FN) plot. The applied voltage is in the range of 260 to $550 \mathrm{~V}$. The FN plot slope is $-2,333$ decade V.

A

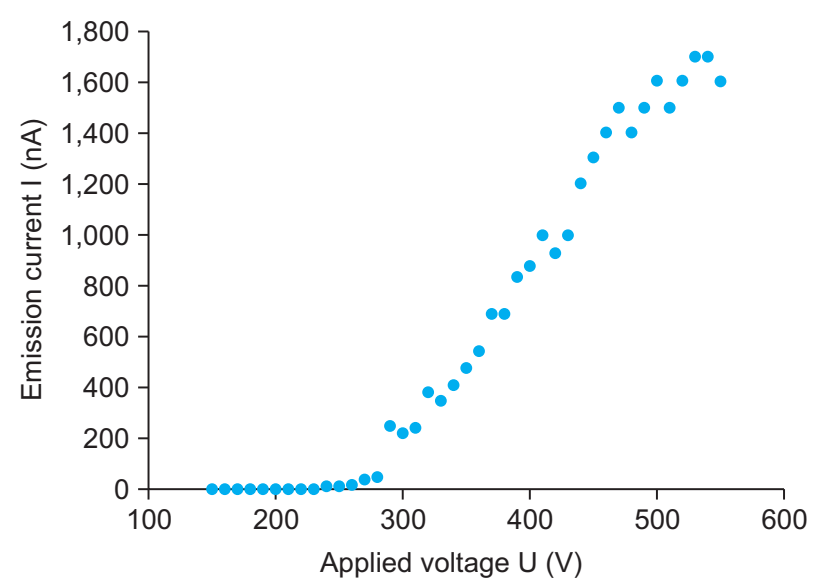

B

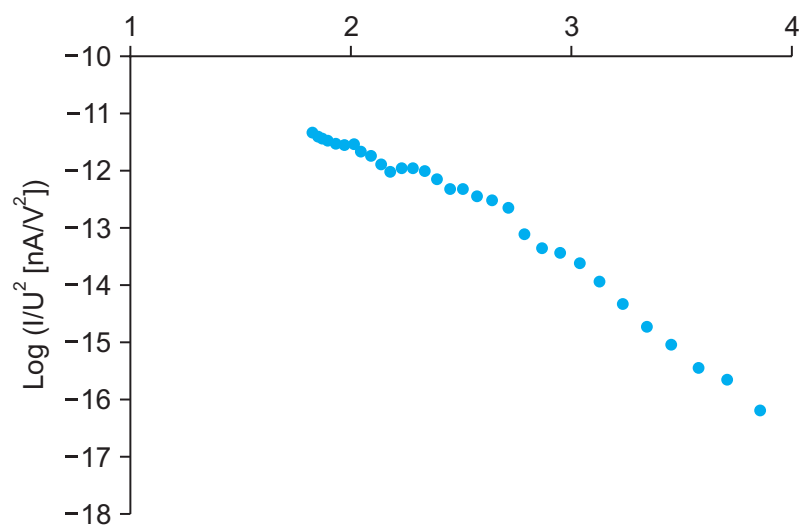

Fig. 2.4. (A) The current-voltage (I-V) characteristics of composite carbon-fiber/CEI-resin, during the first decreasing voltage scan; (B) related FowlerNordheim (FN) plot. The applied voltage is in the range $550 \mathrm{~V}$ down to $150 \mathrm{~V}$ the FN plot slope is $-768 \mathrm{decade} \mathrm{V}$. 

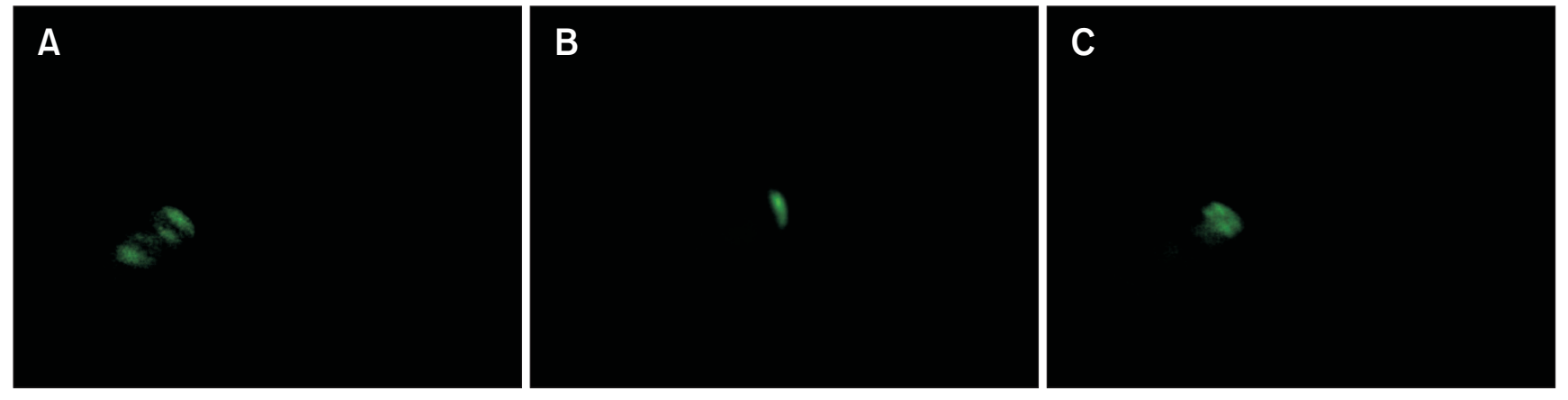

Fig. 2.5. Field electron emission images of composite carbon-fiber/CEI-resin tip. Voltage increase caused the emission current to get stronger, and image spots to get bigger and brighter. Image details are: (A) $510 \mathrm{~V}, 1.0 \mu \mathrm{A}$; (B) $530 \mathrm{~V}, 1.4 \mu \mathrm{A}$; (C) $550 \mathrm{~V}, 1.6 \mu \mathrm{A}$.
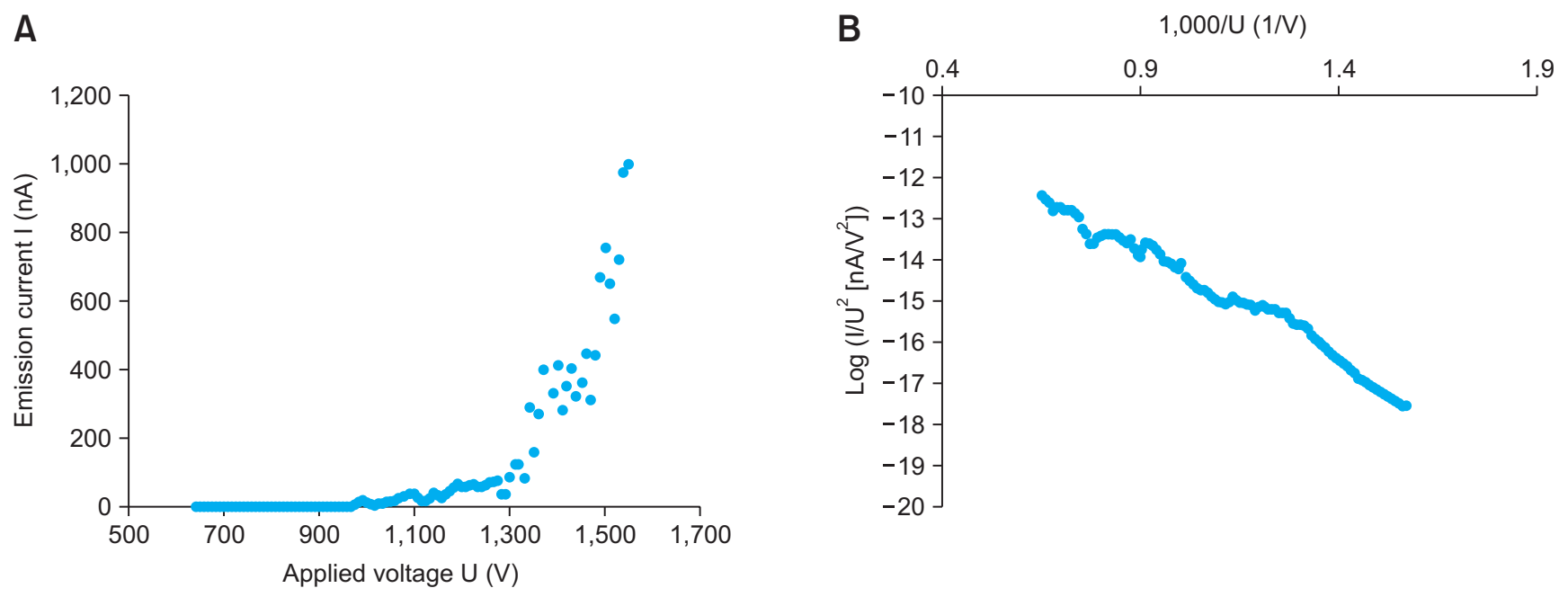

Fig. 3.1. (A) The current-voltage (I-V) characteristics of a clean tungsten tip, taken as the voltage increases; (B) related Fowler-Nordheim (FN) plot. The applied voltage in the range 640 to $1,150 \mathrm{~V}$. The FN-plot slope is -2,314 decade V.
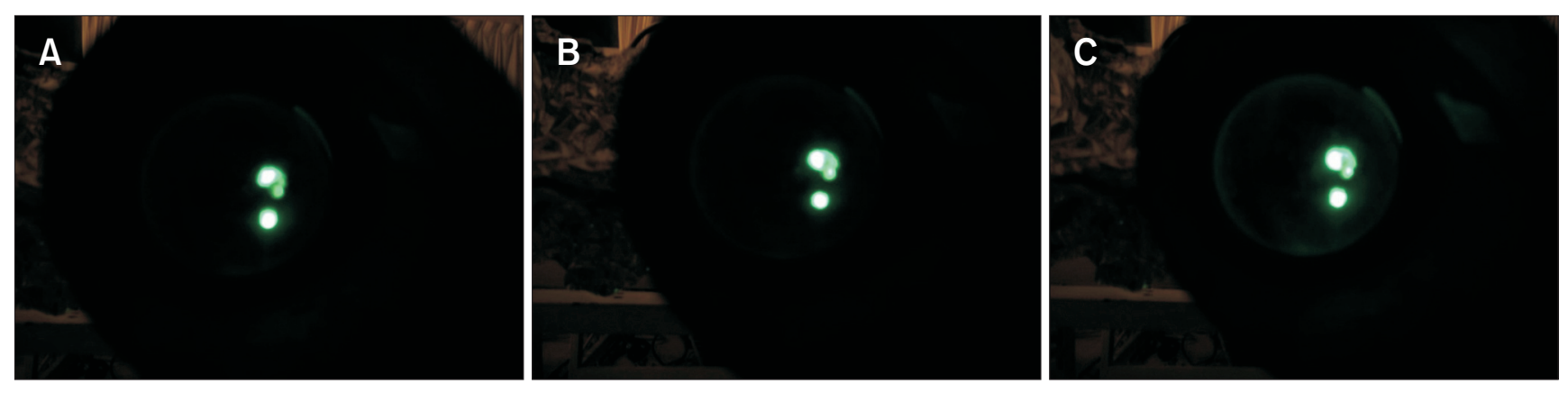

Fig. 3.2. Field electron emission images of clean tungsten tip is distributed in several spots. Voltage increase caused the emission current to get stronger. As can be seen from the emission images, emission spots start to become bigger and/or brighter, as voltage is increased. Image details are: (A) 1,000 V, $970 \mathrm{nA}$; (B) $1,200 \mathrm{~V}, 1.0 \mu \mathrm{A}$; (C) $1,550 \mathrm{~V}, 1.1 \mu \mathrm{A}$.

\section{Composite Tungsten/E6-Resin Emitter}

As above, voltage was applied to the clean tungsten emitter (before coating) and the $I-V$ characteristics were recorded. The emission started at $640 \mathrm{~V}$ with current $8.3 \mathrm{pA}$. Increasing the applied voltage very slowly caused an increase in the emission current; voltages in the range 640 to $1,550 \mathrm{~V}$ gave currents in the range $8.3 \mathrm{pA}$ to $1.1 \mu \mathrm{A}$, as shown in Fig. 3.1A; Fig. 3.1B shows the related FN plots. Fig. 3.2 shows how the emission image relates to emission current.

With the composite tungsten/E6-resin tip, a "switch-on" effect 
again occurred. At the switch-on voltage " $V_{\text {sw }}$ ", the emission current turns on from an effectively zero value to an apparently stable saturated value, namely the "switch-on current" $I_{\text {sat }}$. Switch-on values were $V_{\text {sw }}=12,300 \mathrm{~V}$ and $I_{\text {sat }}=12 \mu \mathrm{A}$.

Fig. 3.3A shows the $I-V$ characteristics for the first decreasing voltage scan, with voltage decreasing from $12,300 \mathrm{~V}$ down to $4,500 \mathrm{~V}$ and current from $12 \mu \mathrm{A}$ down to $5.7 \mathrm{pA}$. Fig. $3.4 \mathrm{~A}$ then shows part of a subsequent increasing-voltage scan, from 500 to $5,300 \mathrm{~V}$, with currents from $13 \mathrm{pA}$ to $1.8 \mu \mathrm{A}$. The right parts of Fig. 3.3 and Fig. 3.4 show the related FN plots. Fig. 3.5 shows how emission images relate to emission current.

\section{Composite Carbon-Fiber/E6-Resin Emitter}

As above, voltage was applied to the clean carbon-fiber tip before coating, and the $I-V$ characteristics were recorded.
Emission started at $400 \mathrm{~V}$, with current $1.1 \mathrm{pA}$. Increasing the applied voltage very slowly caused an increase in the emission current; voltages in the range 400 to $750 \mathrm{~V}$ gave currents in the range $1.1 \mathrm{pA}$ to $1.9 \mu \mathrm{A}$, as shown in Fig. 4.1A; Fig. 4.1B shows the related FN plots. Fig. 4.2 shows the related emission images.

With the composite carbon-fiber/E6-resin emitter, a switchon phenomenon was again observed with the previously untested emitter. At the switch-on voltage $V_{\text {sw }}$, the current jumps from an effectively zero value to an apparently stable, saturated value, namely the "switch-on value" $I_{\text {sat }}$. Values were $V_{\text {sw }}=1,300 \mathrm{~V}$ and $I_{\text {sat }}=5.3 \mu \mathrm{A}$. Fig. $4.3 \mathrm{~A}$ shows the $I-V$ characteristics for the subsequent first decreasing voltage scan: as voltage decreases from $1,300 \mathrm{~V}$ down to $500 \mathrm{~V}$, current decreases from $5.3 \mu \mathrm{A}$ to $3.0 \mathrm{pA}$. In a subsequent voltage-
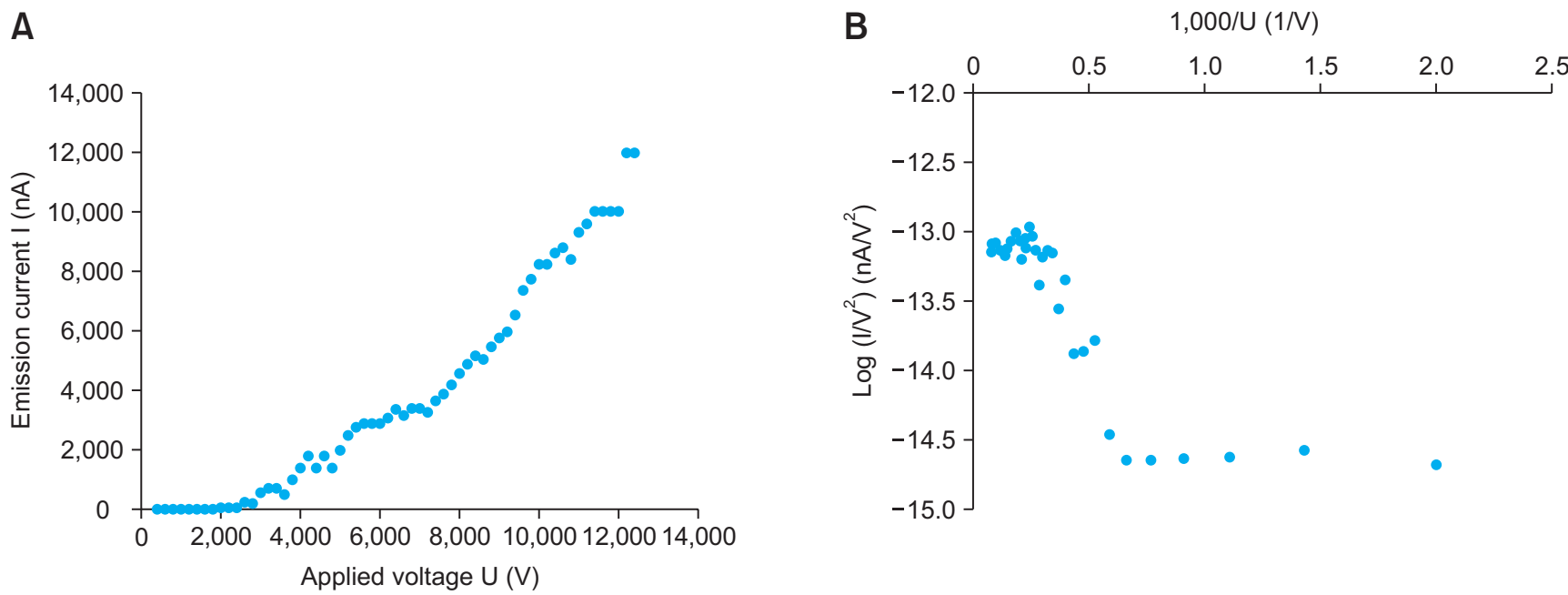

Fig. 3.3. (A) The current-voltage $(I-V)$ characteristics of composite tungsten/E6-resin tip during the first decreasing-voltage scan; (B) related FowlerNordheim (FN) plot. The voltage changes from $12,300 \mathrm{~V}$ down to 4,500 V. The FN-plot slope is -764 decade V.

A

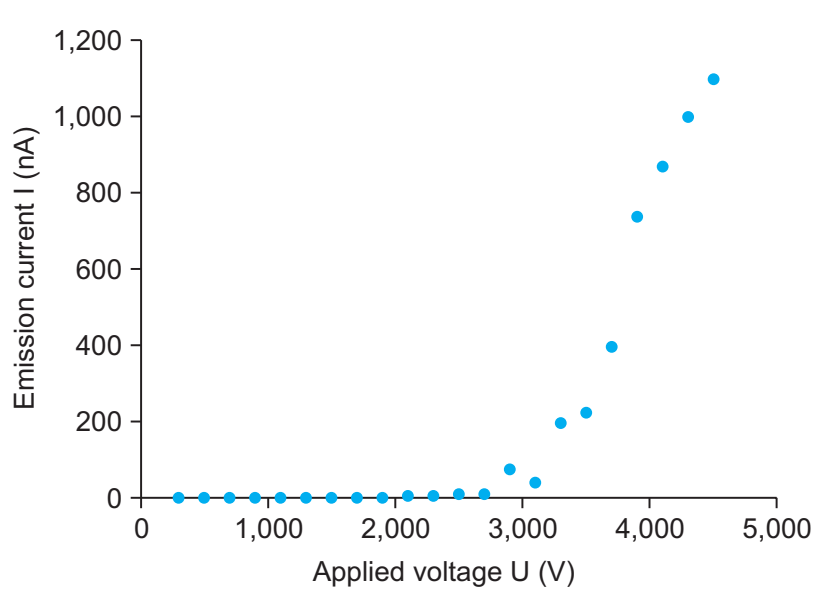

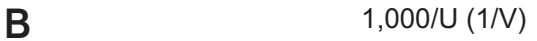

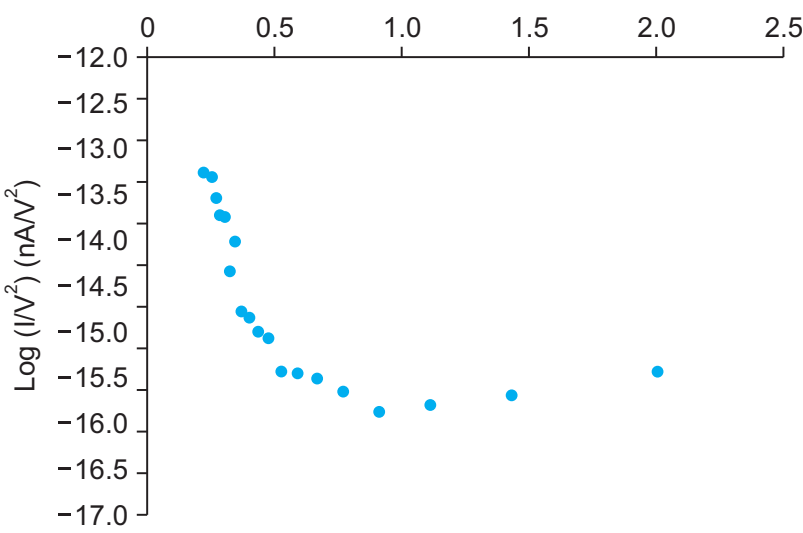

Fig. 3.4. (A) The current-voltage ( $I-V)$ characteristics of composite tungsten/E6-resin tip during the second increasing-voltage scan; (B) Fowler-Nordheim (FN) plot. The applied voltage is in the range of 500 to 5,300 V. The FN plot slope is -768 decade V. 

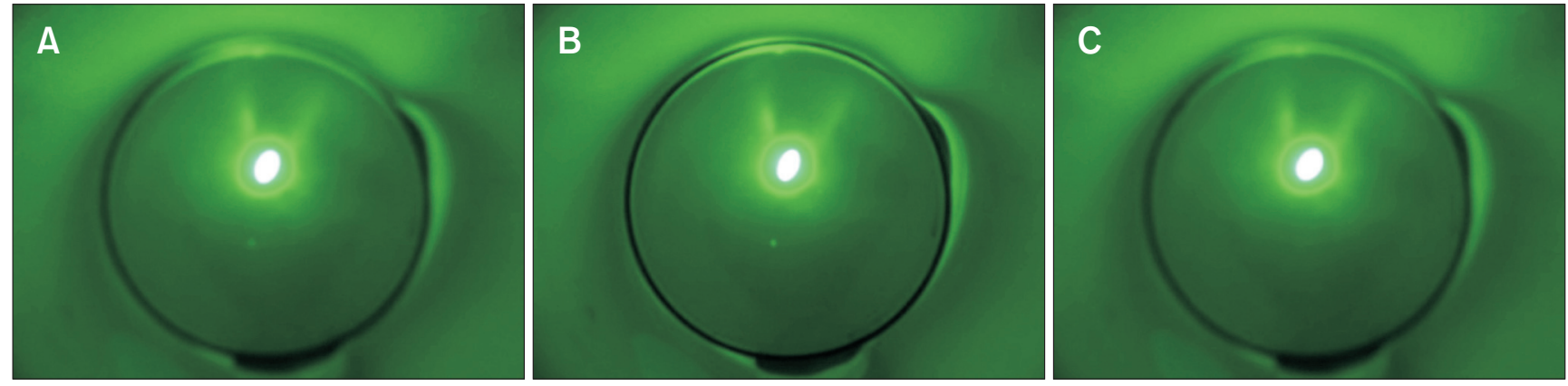

Fig. 3.5. For composite tungsten/E6-resin tip, field electron emission images showing current stability in one high brightness spot. Image details are: (A) $12,100 \mathrm{~V}, 12 \mu \mathrm{A}$; (B) 12,200 V, $12 \mu \mathrm{A}$; (C) 12,300 V, $12 \mu \mathrm{A}$. Time separation between adjacent images is 15 minutes.

A

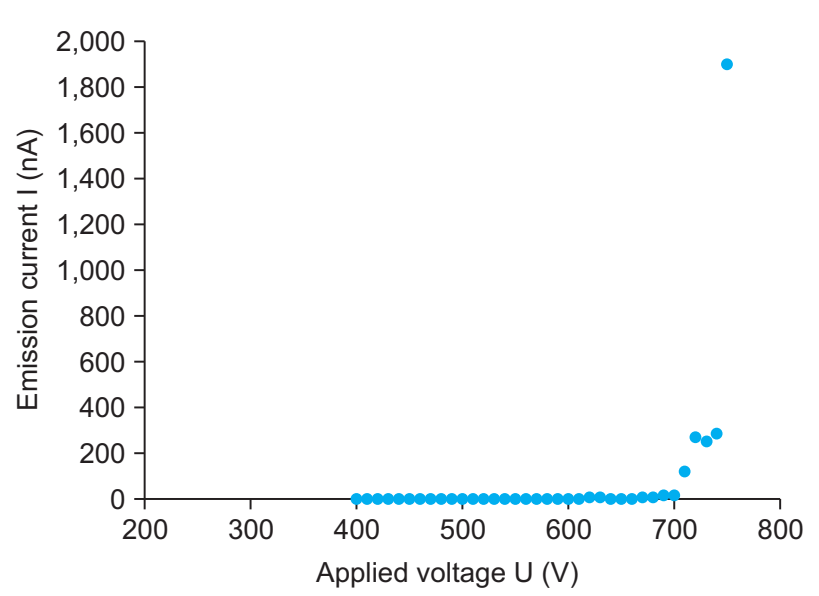

B

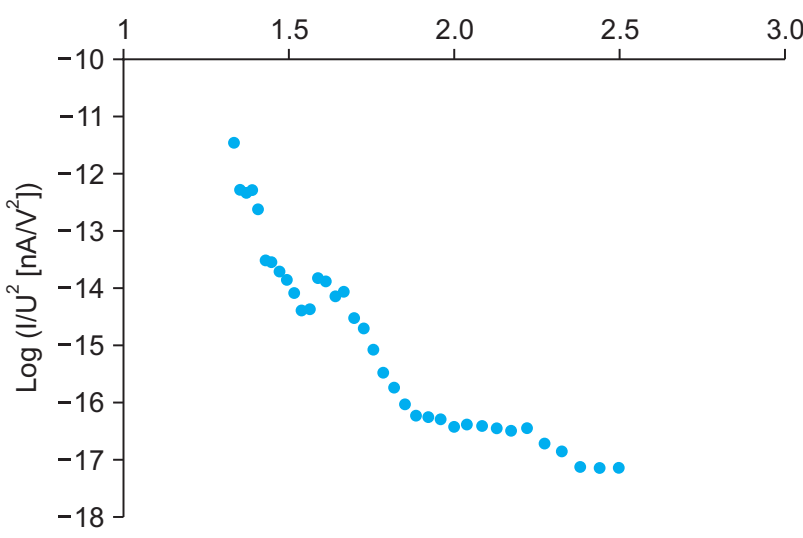

Fig. 4.1. (A) The current-voltage (I-V) characteristics of a clean carbon-fiber tip, taken as voltage increases; (B) related Fowler-Nordheim (FN) plot. The applied voltage is in the range 400 to $750 \mathrm{~V}$. The FN plot slope is $-4,452$ decade $\mathrm{V}$.
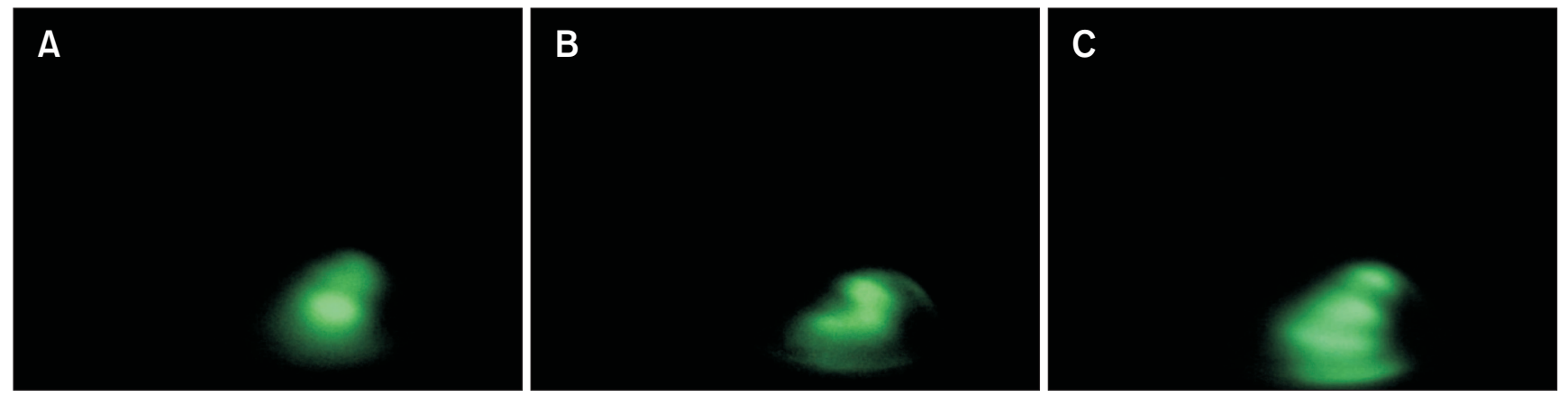

Fig. 4.2. Field electron emission images of clean carbon-fiber tip. Voltage increase caused the emission current to get stronger. As can be seen from the emission images, emission spots start to become bigger and brighter, as voltage is increased. Image details are: (A) $710 \mathrm{~V}, 1.2 \mu \mathrm{A}$; (B) $730 \mathrm{~V}, 1.6 \mu \mathrm{A}$; (C) $750 \mathrm{~V}$, $1.9 \mu \mathrm{A}$.

increasing scan Fig. 4.4, voltage increase from 400 to $790 \mathrm{~V}$ caused current increase from $1.1 \mathrm{pA}$ to $1.0 \mu \mathrm{A}$. The right parts of Fig. 4.3 and Fig. 4.4 show the related FN plots. Fig. 4.5 shows related emission images.

\section{CONCLUSIONS}

Composite emitters, consisting of clean tungsten and carbon fiber tips with known profile, coated by dielectric materials, were investigated. It is found that the field emission 

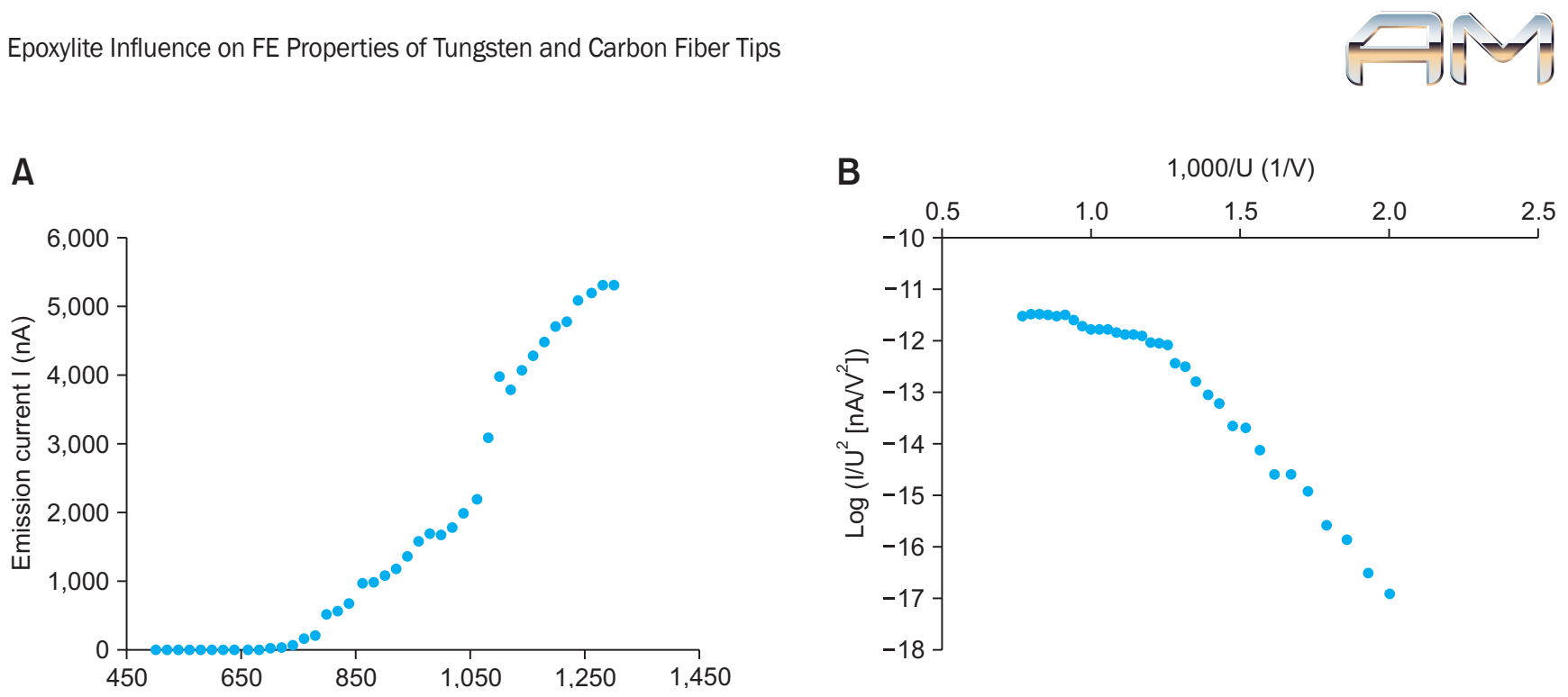

Fig. 4.3. (A) The current-voltage ( $I-V)$ characteristics of composite carbon-fiber/E6-resin tip during the first decreasing-voltage scan, after switch-on at 1,300 $\mathrm{V}, 5.3 \mu \mathrm{A}$; (B) related Fowler-Nordheim (FN) plot. The applied voltage decreases from 1,300 to $500 \mathrm{~V}$. The FN plot slope is $-4,215 \mathrm{dec}$ de $\mathrm{V}$.

A

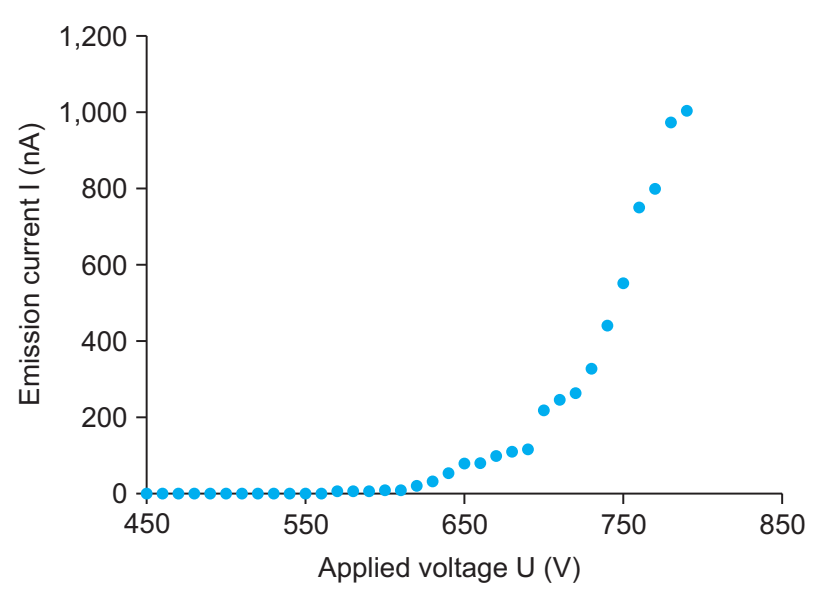

B

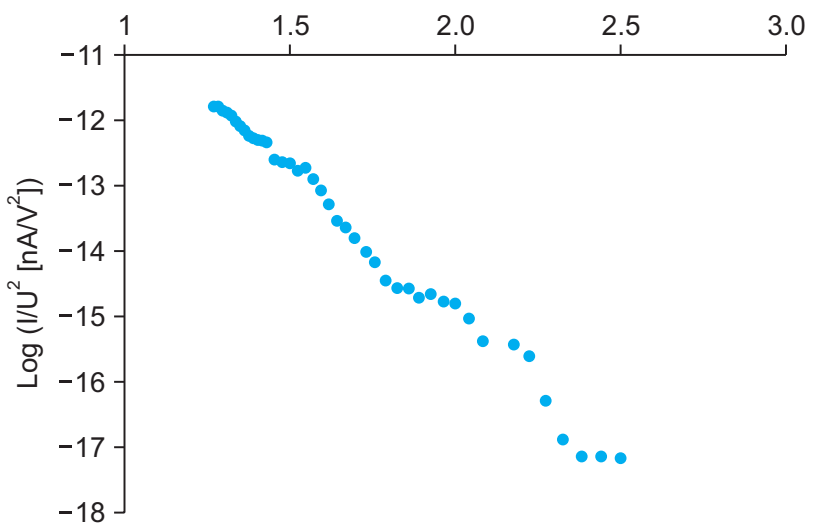

Fig. 4.4. (A) The current-voltage ( $I-V)$ characteristics of composite carbon-fiber/E6-resin tip, during the increasing-voltage scan; (B) related FowlerNordheim (FN) plot. The applied voltage is in the range of 400 to $790 \mathrm{~V}$. The FN-plot slope is $-4,528$ decade V.
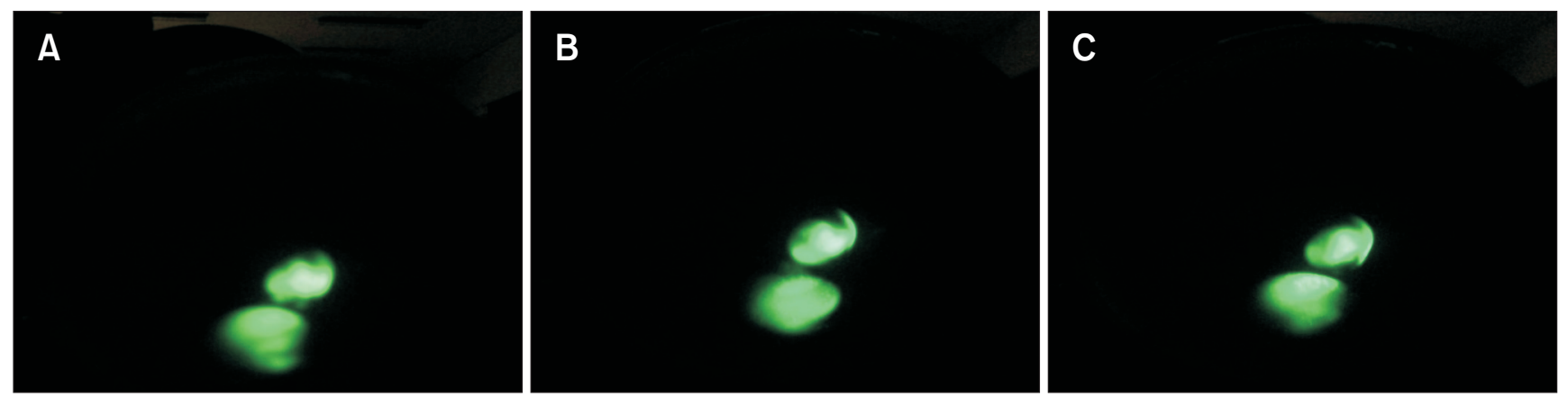

Fig. 4.5. For composite carbon-fiber/E6-resin tip, field electron emission images showing current stability. Image details are: (A) $1,100 \mathrm{~V}, 5.0 \mu \mathrm{A}$; (B) $1,200 \mathrm{~V}$, $5.2 \mu \mathrm{A}$; (C) $1,300 \mathrm{~V}, 5.3 \mu \mathrm{A}$. Time separation between adjacent images is 15 minutes.

characteristics of these micro-emitters are intrinsically changed by coating the emitters with a thin layer of dielectric material, this is in line with the results from previous investigations (Al-
Qudah et al., 2015; Bajic et al., 1989; Latham \& Mousa, 1986; Moran Meza et al., 2015; Mousa, 1987, 1988, 1992, 1994, 2007; Mousa \& Kelly, 2003; Mussa et al., 2012). By comparing 
Table 1. The extent of changes on the current-voltage ( $I-V)$ characteristics of the nano emitters (nanotips) after being coated with epoxylite resin layer of different thickness Clark Electromedical Instrument (CEI)

\begin{tabular}{|c|c|c|c|c|c|c|}
\hline \multirow[b]{2}{*}{ Tip } & \multicolumn{2}{|c|}{ Clean tip characteristic } & \multicolumn{4}{|c|}{ Composites tip characteristic } \\
\hline & $\begin{array}{l}\text { Applied voltage } \\
\text { range }(\mathrm{V})\end{array}$ & $\begin{array}{l}\text { Emission current } \\
\text { range }(\mathrm{n} A)\end{array}$ & $\begin{array}{l}\text { Switch-on } \\
\text { voltage (V) }\end{array}$ & $\begin{array}{l}\text { Switch-on } \\
\text { current }(\mu \mathrm{A})\end{array}$ & $\begin{array}{l}\text { Applied voltage } \\
\text { range (V) }\end{array}$ & $\begin{array}{l}\text { Emission current } \\
\text { range }(\mathrm{nA})\end{array}$ \\
\hline Composite tungsten/CEI-resin emitter & 430 980 & $0.0088 \sim 690$ & 2,300 & 3.3 & $2,300 \sim 200$ & $330 \sim 0.0032$ \\
\hline \multirow[t]{2}{*}{ Composite carbon-fiber/CEI-resin emitter } & $220 \sim 700$ & $0.0022 \sim 2,200$ & - & - & $260 \sim 550$ & $0.0045 \sim 1,400$ \\
\hline & & & - & - & $550 \sim 150$ & $1,600 \sim 0.0012$ \\
\hline Composite tungsten/E6-resin emitter & $640 \sim 1,550$ & $0.0083 \sim 1,100$ & 12,300 & 12 & $12,300 \sim 4,500$ & $12,000 \sim 0.0057$ \\
\hline Composite carbon-fiber/E6-resin emitter & $400 \sim 750$ & $0.0011 \sim 1,900$ & 1,300 & 5.3 & $1,300 \sim 500$ & $5,300 \sim 0.003$ \\
\hline
\end{tabular}

the effects of different coating materials, we find the following effects. Clark Electromedical Instruments Epoxylite resin improves the characteristics of the tungsten emitter more than those of the carbon-fiber emitter. Likewise, Epidian 6 expoxy resin (based on bisphenol A) improved the characteristics of the tungsten emitter more than the characteristics of the carbon-fiber emitter, Table 1 shows the extent of changes on the $I-V$ characteristics of the nanoemitters after being coated with dielectric layer. The composite samples reported in this work could be considered as a potential powerful electron source for technical uses. The produced electron beam can be employed in many applications such as been reported by Lee et al. (2015) where the beam was used in transmission electron microscopy for sample preparation of $\mathrm{Ge}_{2} \mathrm{Sb}_{2} \mathrm{Te}_{5}$.

\section{CONFLICT OF INTEREST}

No potential conflict of interest relevant to this article was reported.

\section{ACKNOWLEDGMENTS}

Ala’a M. Al-Qudah, Emad S. Bani Ali and Ayman Almasri would like to express gratitude to the Scientific Research Support Fund SRSF in the Hashemite Kingdom of Jordan for financial support that enabled completing this research work.

\section{REFERENCES}

Alnawasreh S, Mousa M S, and Al-Rabadi A N (2015) Investigating the effects of sample conditioning on nano-apex carbon fiber tips for efficient field electron emission. Jo. J. Phys. 2, 95-101.

Al-Qudah A M, Mousa M S, and Fischer A (2015) Effect of insulating layer on the field electron emission performance of nano-apex metallic emitters. IOP Conf. Ser.: Mater. Sci. Eng. 92, 012021.

Bajic S, Mousa M S, and Latham R V (1989) Factors influencing the stability of cold-cathodes formed by coating a planar electrode with a metal-insulator composite. J. Phys. (Paris) 50, C8 79-84.

Forbes R G (2012) Extraction of emission parameters for large-area field emitters, using a technically complete Fowler-Nordheim-type equation. Nanotechnology 23, 095706.

Forbes R G, Deane J H B, Fischer A, and Mousa M S (2015) FowlerNordheim plot analysis: a progress report. Jo. J. Phys. 8, 125-147.

Latham R V and Mousa M S (1986) Hot electron emission from composite metal-insulator micropoint cathodes. J. Phys. D: Appl. Phys. 19, 699-713.

Lee H S, Lee J Y, and Yeo J S (2015) Transmission electron microscopy sample preparation of Ge2Sb2Te5 nanowire using electron beam. Appl. Microsc. 45, 199-202.

Lilienfeld J R (1922) The auto electronic discharge and its application to the construction of a New form of X-ray tube. Am. J. Roentgenol. 9, 172-179.

Madanat M A, Mousa M S, Al-Rabadi A N, and Fischer A (2015) Electronmicroscopy-based performance evaluation of various tungsten field- emitter tips apex radii. Jo. J. Phys. 8, 79-85.

Moran Meza J A, Lubin C, Thoyer F, Villegas Rosales L A, Guitarra Espinoza A A, Martin F, and County J (2015) Fabrication of ultra-sharp tips from carbon fiber for scanning tunneling microscopy investigations of epitaxial graphene on 6H-SiC(0001) surface. Carbon 86, 363-370.

Mousa M S (1987) Study of field induced hot-electron emission using the composite microemitters with varying dielectric layer thickness. J. Phys. (Paris) 48, C6 115-120.

Mousa M S (1988) Effect of Lacomit films on cold-cathode hot-electron emission. J. Phys. (Paris) 49, C6 237-242.

Mousa M S (1990) A new perspective on the hot-electron emission from metal-insulator microstructures. Surf. Sci. 231, 149-159.

Mousa M S (1992) Field electron emission studies on zinc oxide coated tungsten micro emitters. Surf. Sci. 266, 110-120.

Mousa M S (1994) Investigations of in-situ carbon coating on field emitter arrays. Vacuum 45, 241-244.

Mousa M S (2007) Influence of a dielectric coating on electron emission from micropoint electron sources. Surf. Interface Anal. 39, 102-110.

Mousa M S, Alnawasreh S, Madanat M A, and Al-Rabadi A N (2015) Investigating of the field emission performance on nano-apex carbon fiber and tungsten tips. IOP Conf. Ser.: Mater. Sci. Eng. 92, 012022.

Mousa M S and AI Share M (1999) Study of the MgO-coated W emitters by field emission microscopy. Ultramicroscopy 79, 195-202.

Mousa M S, Brugat M, Sheshin E P, and Hagmann M J (2001) Prototypes 
using metal, carbon fiber and composite field emission sources modulated by a laser beam. Ultramicroscopy 89, 129-135.

Mousa M S, Fischer A, and Mussa K O (2012), Metallic and composite micropoint cathodes: aging effect and electronic and spatial characteristics. Jo. J. Phys. 1, 21-26.

Mousa M S and Kelly T F (2003) Stabilization of carbon-fiber cold fieldemission cathodes with a dielectric coating. Ultramicroscopy $\mathbf{9 5}$, 125-130.
Murphy E L and Good R H (1956) Thermionic emission, field emission and the transition region. Phys. Rev. 102, 1464-1473.

Mussa K O, Fischer A, and Mousa M S (2012) Characterizing a new composite material: effect of $\mathrm{NaOH}$ coating of variable thickness on the properties of a tungsten microemitter. Jo. J. Phys. 5, 27-31.

Winkler J H (1744) Gedanken von den Eigenschaften, Wirkungen und Ursachen der Electrizität nebst Beschreibung zweier electrischer Maschinen (Verlag B. Ch. Breitkopf, Leipzig). 